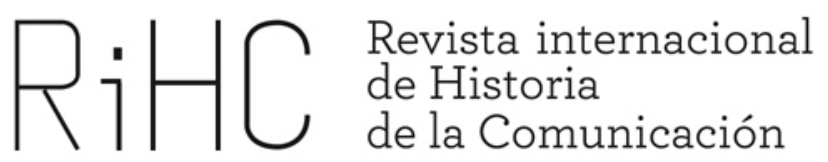

\title{
JAIME CLARAMUNT, EL CUBANO QUE DIRIGIÓ EL DILUVIO, DIARIO REPUBLICANO DE BARCELONA
}

Jaime Claramunt, the cuban director of El Diluvio, a republican newspaper of Barcelona

DOI: http://dx.doi.org/10.12795/RiHCCC.2017.i08.02

Gil Toll

Universitat Autònoma de Barcelona

giltoll@yahoo.com

Recibido: 9-4-2017

Aceptado: 24-5-2017

Resumen: El diario El Diluvio de Barcelona se publicó entre 1858 (inicialmente como El Telégrafo) y 1939. Jaime Claramunt, periodista nacido en la Cuba colonial, entró en su redacción en 1894 y dirigió el periódico entre 1916 y 1938. Su profunda huella en el periódico republicano y popular más influyente de Barcelona podemos seguirla ahora con las memorias del periodista halladas en el Archivo Nacional de Cuba, país en el que vivió sus últimos años tras la guerra civil y su exilio político. Los papeles de Claramunt fueron redactados en forma de conferencias que el periodista pronunció en la emisora gubernamental CMZ en la década de los 40. En ellos hay elementos autobiográficos, informaciones sobre el funcionamiento del periódico y sobre la biografía de sus periodistas. Además, Claramunt nos da sus opiniones sobre el mundo de la política del periodo y los trascendentes hechos que vivió como director de El Diluvio. 
Palabras clave: Prensa de Barcelona; Directores de periódicos; Relaciones hispanocubanas; Restauración; Dictadura de Primo de Rivera; Segunda República; Guerra Civil

Abstract: The Barcelona daily EI Diluvio was published between 1858 (initially as EI Telegrafo) and 1939. Jaime Claramunt, journalist born in colonial Cuba, entered its newsroom in 1894 and directed the newspaper between 1916 and 1938. His deep imprint on the republican and most influential popular newspaper of Barcelona can be traced now with the memories of the journalist found in the National Archives of Cuba, a country where he lived his last years after the civil war and political exile. Claramunt papers were written in the form of lectures that the journalist gave at the government station $C M Z$ in the decade of the 40. In them there are autobiographical elements, information on the operation of the newspaper and the biography of its journalists. In addition, Claramunt gives us his views on the world of politics of the period and significant events that lived as director of El Diluvio.

Keywords: Barcelona press; Newspaper editors; Spanish-cuban relations; Restauration; Primo de Rivera dictatorship; Second Spanish Republic; Civil War

\section{Introducción y metodología}

El Diluvio fue, en los años de la II República, el segundo diario en importancia de la ciudad de Barcelona. Sus gestores le atribuían una tirada de 150.000 ejemplares y ese dato se recoge en fuentes citadas habitualmente en trabajos académicos ${ }^{1}$.

El periódico se definía políticamente como republicano y federalista e invocaba la figura de Francesc Pi i Margall como referente de sus postulados. Sin embargo, no era un diario de partido, sino de empresa, la de la familia Lasarte, vinculada a la fundación del diario en 1858 con el nombre de El Telégrafo.

De hecho, el cambio de nombre del periódico se produjo en numerosas ocasiones desde su fundación hasta 1879 , en que adopta su definitiva cabecera. La causa no era otra que los problemas con la justicia, que a menudo sentenciaba la suspensión de la publicación. Los editores entonces recurrían al ardid de cambiar la cabecera y continuar saliendo a la calle. El Principado, La Imprenta, Crónica de Cataluña o El Látigo fueron algunos de los nombres utilizados.

Todo ello venía provocado por los contenidos de un periódico que cuestionaba la monarquía, el estado centralista, el colonialismo y que tenía uno de sus ejes

\footnotetext{
${ }^{1}$ Es el caso del anuario Schwartz-rot-Buch de 1935
} 
principales en el anticlericalismo. Tras la temprana muerte del fundador, Ferran Patxot, quedó al frente del periódico Manuel de Lasarte Rodríguez Cardoso. Autor de numerosos folletines que se publicaron en el diario, Lasarte frecuentaba la rebotica de la relojería de Frederic Soler, Pitarra, el autor de teatro popular de la Barcelona de fin de siglo con el que también compartía ideología republicana y federal (Roure, 2010).

Sobre los primeros años del periódico, con el nombre de El Telégrafo, sí ha trabajado brillantemente el profesor Jaume Guillamet (2010), gracias a quien sabemos que el periódico supuso una eficaz alternativa al entonces dominante Diario de Barcelona. La apuesta por unos contenidos progresistas con precios más populares le otorgó el favor del público y en 1873 proclamaba el liderazgo de la prensa catalana con 10.000 ejemplares de tirada. Una cifra que hay que multiplicar varias veces para obtener la audiencia real, pues los periódicos y éste en especial, se leían en voz alta en bares y talleres para superar el alto grado de analfabetismo del país.

De aquellos años datan posicionamientos públicos del diario en favor del sistema federal de organización del Estado o de la ley de matrimonio civil. En este último caso cabe situar el inicio de la reputación anticlerical del periódico que más tarde profundizó con entusiasmo.

El Diluvio tenía otra de sus señas de identidad en la voluntad de defensa de los intereses ciudadanos ante el poder municipal en Barcelona. Así, el cambio de nombre definitivo devino a causa del enfrentamiento del periódico con el Ayuntamiento con motivo de una tasa municipal sobre el consumo de gas doméstico que se quiso imponer a los consumidores. El diario llamó a la insumisión fiscal y, tras numerosos avatares, se acabó suprimiendo la tasa.

En la última década del siglo XIX Barcelona vivió una etapa de reivindicaciones sociales que tuvieron al anarquismo como fuerza política emergente. La campaña de atentados con bomba protagonizada por los más exaltados tuvo una dura respuesta oficial con la detención de centenares de simpatizantes de la causa obrera. En el castillo de Montjuic se produjeron graves abusos sobre los detenidos que permanecían entre muros largos meses. Joan Montseny fue uno de ellos y denunció la situación creada a través de una serie de cartas que salieron clandestinamente de la cárcel y fueron publicadas en El Diluvio con el seudónimo de Federico Urales, que se haría posteriormente muy popular (Dalmau, 2010).

En 1904 murió Manuel de Lasarte Rodríguez Cardoso, fundador del diario junto a Ferran Patxot. Le sucedió al frente de la empresa Manuel de Lasarte Arán, de carácter muy distinto al literato y político que fue su padre. El joven era apocado, pero tenía en su mujer, María Ángeles Busquets, un contrapunto de fuerza de voluntad. La esposa era miembro de una familia dedicada a los negocios químicos y petrolíferos que años más tarde tendría una importante actividad en la prensa española con la Sociedad 
Editora Universal, propietaria de un importante grupo de prensa en el que destacaba Heraldo de Madrid (Toll, 2013). Ante la responsabilidad de gestionar la empresa tras la muerte del patriarca, María Ángeles buscó la colaboración de su hermano, Manuel Busquets George, que ya se distinguía por su dinamismo empresarial. Estuvo en El Diluvio como administrador unos años, en los que se decidió la compra de una nueva rotativa y se puso en marcha un suplemento ilustrado para competir con la prensa satírica del momento.

Las páginas de El Diluvio contaron con la colaboración de notables plumas del republicanismo, como Roberto Castrovido o Antonio Zozaya, y de políticos como Lluís Companys. El corresponsal más singular de su ápoca, Luis Bonafoux, escribió para el periódico desde París al tiempo que lo hacía para Heraldo de Madrid. En la redacción trabajó un tiempo Andreu Nin, que más tarde lideraría el POUM. En la nómina de ilustradores se cuenta a Ricard Opisso, mientras que en la de fotógrafos estaba Joaquim Brangulí.

Las memorias del anarquista Pere Foix (Foix, 1976) narran el día del asesinato del líder anarcosindicalista Salvador Seguí, el noi del sucre, en 1923. Tras conocer la noticia en plena calle, Foix se dirigió a la redacción de El Diluvio, donde se encontró con el redactor Eduardo Sanjuan, que lloraba a lágrima viva, y con el director, Jaime Claramunt, que exclamaba su convencimiento de que el atentado había sido obra del Sindicato Libre, la organización violenta de la patronal que se enfrentaba a los anarquistas. Queda así consignada la estrecha relación del periódico con el movimiento obrero barcelonés que entonces se identificaba mayoritariamente con el anarquismo.

El 12 de abril de 1931, El Diluvio publicaba una editorial en la que llamaba a votar por las candidaturas republicanas, aunque se lamentaba de la fragmentación de esa opción con la presentación de cinco listas distintas en la ciudad de Barcelona. Identificaba a la Lliga Regionalista de Cambó con la monarquía y les reprochaba duramente haber pasado de ser un quebradero de cabeza para la España oficial a muleta de Alfonso XIII. Dos días después, el periódico publicaba los grandes resultados obtenidos por los republicanos, que sumaron 38 concejales ante 12 monárquicos. Eduardo Sanjuan afirmó en un comentario que la monarquía se asemejaba a una anciana llena de afeites y retoques, que caería si se la empujaba un poco fuerte, por lo que no había tiempo que perder. Palabras que se convirtieron en realidad al cabo de unas horas de su publicación con la proclamación de la República desde el balcón del Ayuntamiento por Lluís Companys, viejo amigo de la redacción de El Diluvio y colaborador en sus páginas.

En 1933, El Diluvio cumplió 75 años de publicación con un folleto en el que aparecían sus diferentes cabeceras desde que apareció como El Telégrafo en 1858. Con la República rigiendo en España y el Estatuto de Autonomía en Cataluña, puede decirse 
que los ideales políticos republicanos y federales del periódico se habían cumplido. Su situación económica era la mejor de su historia, pues en 1929 se había trasladado el periódico a un edificio de propiedad en la calle Consell de Cent, entre el Passeig de Gràcia y la Rambla de Catalunya. A lo que hay que añadir la compra de una nueva rotativa en 1932 capaz de imprimir 60.000 ejemplares de 32 páginas en una hora.

Desde esta seguridad económica y política, El Diluvio intervenía en la vida pública de forma muy activa. En las elecciones de 1933 las opciones republicanas se presentaban una vez más divididas y el periódico presentó una lista con candidatos de Esquerra Republicana y Acció Republicana que cosechó importantes resultados. En diciembre del mismo año, ante la muerte súbita del presidente Francesc Macià, Jaime Claramunt lanzó desde las páginas del diario la candidatura de Lluís Companys como presidente de la Generalitat en un episodio recogido en sus memorias.

Al estallar la guerra civil española, el diario se posiciona sin dudarlo y el 25 de julio publica a toda plana el titular "No pasarán", que se convirtió en el lema del bando republicano durante la contienda. La familia propietaria permaneció en Barcelona durante todo el conflicto y la dirección siguió en manos de Jaime Claramunt hasta 1938. Entonces, el gobierno de Juan Negrín permitió la incautación de El Diluvio por la UGT del País Vasco, que nombró un nuevo director, aunque intentó actuar de forma conciliadora.

La inminente entrada de los franquistas en Barcelona provocó el éxodo de miles de republicanos hacia Francia y con ellos fueron numerosos periodistas del diario, incluyendo al ex director, Jaime Claramunt. Manuel de Lasarte permaneció en la ciudad transmitiendo a sus próximos que no temía la represión por no haber cometido delito de sangre alguno. Lo mismo hizo el jefe de redacción, Frederic Pujulà. Ambos, junto a los hijos de Lasarte, Juan y José, fueron encarcelados. Mientras tanto, la sede del periódico era asaltada por una turba incontrolada $y$, al parecer, se quemaron numerosos documentos. Al cabo de tres meses en prisión, Manuel de Lasarte falleció de una afección renal que, a juicio de sus familiares, fue desatendida por los funcionarios ${ }^{2}$.

A pesar de su fallecimiento, Manuel de Lasarte fue sometido a juicio de responsabilidades políticas y en 1940 se sentenció que su actividad como editor le convertía en "uno de los principales inductores de la subversión en España", por lo que se procedía a la incautación de todos sus bienes. Ello incluía el edificio donde se ubicaba el periódico, toda la maquinaria que en él había y las diversas fincas rústicas propiedad del editor. En 1955 los herederos de Lasarte consiguieron la exención de responsabilidad de la Comisión de liquidación que sucedió al Tribunal de responsabilidades políticas. La recuperación de los bienes se prolongó durante años. La

\footnotetext{
${ }^{2}$ Entrevista del autor con Elisabet de Lasarte, nieta del editor.
} 
rotativa, que fue a parar a la cárcel de Alcalá de Henares, fue uno de los bienes que la familia trató de recuperar en el propio penal con la sentencia en la mano y acompañados por su abogado. Sin embargo, los efectivos de la Guardia Civil que custodiaban la entrada impidieron el acceso encañonando a los Lasarte con sus armas. Ya en la década de los 80 un nuevo intento de localización de la maquinaria no tuvo impedimentos de esa índole, pero la antigua rotativa se había convertido en un amasijo de hierros totalmente inservible.

Así como todo estudiante de periodismo está familiarizado con Agustí Calvet, Gaziel, y sus memorias de director de La Vanguardia en los decisivos años de la República, nadie tenía noticia hasta ahora de los recuerdos del director de El Diluvio, Jaime Claramunt.

Sus textos son totalmente desconocidos, casi como su propia figura. $Y$, sin embargo, se hallaban perfectamente conservados en el Archivo Nacional de Cuba. Fueron a parar allí porque Claramunt, ya en su exilio, colaboró asiduamente en la emisora CMZ del ministerio de Educación cubano con una emisión titulada "Recuerdos de un viejo reportero" (Toll, 2016). Fue a finales de la década de los 40 y probablemente ese trabajo sirvió para que Claramunt recibiera unos ingresos del gobierno cubano cuando ya era un anciano de 80 años.

El acceso a estos documentos ha sido posible por el trabajo investigador de Jorge Domingo Cuadriello, que ha escrito sobre el exilio español en Cuba (2009) y la colaboración de la historiadora Aisnara Perera, que realizó el trabajo de campo en colaboración con el autor.

Claramunt define sus textos como conferencias. Tienen una extensión media de unas mil palabras y su tono es decididamente divulgativo, dirigido al gran público que pudiera escuchar las emisiones de CMZ.

Este artículo pretende enmarcar la aportación de Jaime Claramunt, sistematizar las ideas que se desprenden de sus memorias y ponerlas en su justo valor a través del análisis de su contenido y del contexto histórico en que transcurrieron los hechos relatados.

\section{Jaime Claramunt}

Jaime Manuel Claramunt Mesa nació en Guanabacoa, localidad vecina de La Habana en 1870 y murió en la capital cubana en 1950. Su vocación periodística fue bien temprana, pues ya en la escuela primaria editó un periódico, actividad que prosiguió durante sus estudios secundarios. Llegó a Barcelona en 1893 y se incorporó al 
periódico El Suplemento con 23 años. En el mes de mayo del año siguiente pasó a formar parte de la redacción del diario El Diluvio, del que se convertiría en director en 1916 y hasta 1938, cuando fue apartado del cargo por los responsables de la UGT que incautaron el periódico a finales de la guerra civil.

En sus memorias, Jaime Claramunt se nos presenta como un nacionalista cubano que desde su llegada a la ciudad de Barcelona defendió la causa de la independencia. Lo hizo en la clandestinidad, como corresponsal del diario La republique cubaine que dirigía en París Ramón Betances. Ello le valió el ingreso en prisión, donde trabó amistad con activistas locales contrarios a la guerra de Cuba.

Tras este periodo convulso, Claramunt continuó su defensa de la causa cubana con su pluma. Entre 1910 y 1916 dirigió la revista Cuba en Europa, que tenía por objetivo el fomento de las relaciones económicas entre el nuevo país y el viejo continente. La revista contaba con el amparo del consulado cubano en Barcelona y la aportación de importantes empresarios con intereses en la isla.

El periodista se atribuye también una actitud muy colaboradora con los intereses cubanos desde la dirección de El Diluvio publicando informaciones que fueran beneficiosas para el país. Sin duda el énfasis en esta cuestión en sus conferencias hay que verlo en el contexto de sus intervenciones en la emisora $\mathrm{CMZ}$, del ministerio de educación del gobierno de Cuba.

De la vida personal de Jaime Claramunt sabemos que estuvo casado con Ana Guix Carreras, bailarina y modelo a la que llevaba casi 20 años de diferencia. Ello fue determinante en el duro trámite de la marcha a pie por las montañas camino del exilio en 1939. Claramunt relata cómo su mujer le cargó durante parte del trayecto debido a su precario estado de salud consecuencia de las privaciones sufridas.

Gracias a su nacionalidad cubana, la pareja pudo viajar a la isla más rápidamente que otros exiliados. El gobierno le favoreció con un empleo en el ministerio de educación junto a otros periodistas y escritores como Juan Chabás, José Luis Galbe o Nicolás Rodríguez, que también colaboraron en la emisora CMZ.

El estilo de redacción de los textos de Claramunt es de una gran claridad, como no podía ser de otra forma al tratarse de un periodista de más de cuatro décadas de trayectoria. Sus inicios decimonónicos se sienten en el léxico, en algunas formas gramaticales y en cierta ampulosidad retórica. Hay que convenir que las memorias fueron escritas en el exilio y sin la ayuda de un soporte documental que habría brindado mayor riqueza informativa y la omisión de algunos errores de nombres mencionados.

En cuanto a la ideología, Jaime Claramunt se define en primer lugar como republicano federalista, seguidor de Francesc Pi i Margall, a quien se invoca también como 
inspirador de la línea editorial de El Diluvio. El periodista marca distancias con el socialismo, el comunismo o el anarquismo y, sin embargo, declara sus simpatías por la causa obrera. Lo hace desde una posición externa, de pequeña burguesía, que en el ambiente republicano de Barcelona tuvo un interés coincidente en la abolición de la monarquía y la democratización de la economía dirigida por una gran burguesía que en buena parte simpatizaba con el rey y se beneficiaba de un trato preferente del Estado.

\section{El periodismo según Jaime Claramunt ${ }^{3}$}

Las conferencias de Claramunt nos permiten hacernos una idea general de la visión de la profesión periodística del director de El Diluvio. El autor presenta un rápido repaso a las principales cabeceras aparecidas en Madrid y Barcelona en el primer tercio del siglo $X X$ y establece una línea de progresiva liberalización del pensamiento desde EI Imparcial, a El Liberal, El Progreso, El País, Heraldo de Madrid y EI Sol. Esta es la prensa que merece la consideración del autor y entre ella destaca a su propio periódico, al que sitúa "a la altura de los más elevados ideales en la prensa hispana".

Contrasta esta selección con otra prensa a la que califica de informativa y que descalifica por la búsqueda de beneficios mediante la adulación y la venta de sus espacios informativos. En esta categoría, Claramunt sitúa La Correspondencia de España y El Noticiero Universal. El nexo común de ambas publicaciones es Francisco Peris Mencheta, que fuera redactor de La Corres y director del Ciero. Se adivina una inquina personal en el tono de las consideraciones de Claramunt hacia su antiguo rival, a quien acusa de realizar concesiones inconfesables. También arroja bilis sobre Alejandro Lerroux, de quien hace un breve resumen biográfico centrado en sus inicios periodísticos. Más adelante, Claramunt explica cómo le dedicó un libro El peor enemigo de la República (Claramunt, 1934) que el entonces jefe de gobierno mandó recoger en las librerías y quioscos de toda España.

El autor, por tanto, mezcla sus sentimientos personales con el análisis de la prensa de su época. Claramente se pronuncia a favor de la prensa idealista, la que defiende una causa o unas ideas políticas, frente a la prensa entendida como mero negocio, a la que achaca una falta de escrúpulos que la llevan a vender sus espacios al mejor postor.

Pero la prensa idealista en la España de la Restauración topaba con las leyes de imprenta vigentes y con la actuación de los fiscales de imprenta, a los que Claramunt

\footnotetext{
${ }^{3}$ Las ideas de Jaime Claramunt sobre periodismo se desprenden de las conferencias agrupadas bajo en título "El Diluvio desde dentro" en TOLL, 2016 p. 37-58.
} 
describe como "lo peor de la empleomanía oficial" y a los que atribuye la realización de "auténticos disparates".

Claramunt explica cómo El Diluvio debió afrontar en múltiples oportunidades la represión de la libertad de expresión y nos revela sus trucos para evitar males mayores.

Cuando un tribunal dictaba la suspensión del periódico por alguna causa abierta, los editores decidían un cambio en el nombre de la cabecera y seguían publicándolo. Ya hemos referido que el primer nombre del periódico fue El Telégrafo y que cambió en repetidas ocasiones hasta 1879 , en que el enésimo enfrentamiento con la justicia hizo surgir el nombre de El Diluvio como alternativa para mantener la publicación con vida.

Otra táctica para superar el cerco legal que suponían los tipos penales de la injuria y la calumnia era el nombramiento de directores de paja. Claramunt explica esta figura como la del personaje que se aviene a pasar temporadas en la cárcel asumiendo las culpas de los profesionales del periodismo que serían los responsables reales del hecho juzgado. Sin embargo, el periodista advierte que estas figuras de nada servían cuando se declaraba el estado de guerra en el país, pues bajo la ley marcial, los militares detenían y encarcelaban a los auténticos directores sin más miramientos legales.

Jaime Claramunt también dirige su mirada hacia las condiciones socioeconómicas de la profesión periodística en su tiempo. De inicio advierte de la mala consideración del periodismo por la sociedad española, que sitúa a la cola de Europa. La concreción de esta mala imagen sería la deficiente remuneración de los profesionales, que en su mayoría debían buscar otras fuentes de ingresos para sobrevivir.

Claramunt aporta datos muy concretos sobre esta realidad y afirma que en sus inicios como redactor, en 1893, cobraba 150 pesetas mensuales. Y nos aporta la información de que el sueldo del director del Diario de Barcelona, Juan Mañé y Flaquer, nunca habría llegado a las 500 pesetas. La modestia en los ingresos también habría afectado al director del órgano portavoz del Partido Conservador, La Dinastía, que apenas sumaría 250 pesetas de mensualidad. En su comentario, Claramunt no puede evitar saldar nuevamente cuentas pendientes, en este caso con Modesto Sánchez Ortiz, que fuera director de La Vanguardia, y al que descalifica como pretencioso e ignorante además de tacaño en el trato económico con sus subordinados.

Jaime Claramunt también posa su lupa sobre algunos de sus colaboradores en el periódico para acercar características de su personalidad que tienen aires de naturalismo. Así, describe al periodista Juan Ambrosio Pérez como un buen profesional del periodismo vencido por su adicción al alcohol y finalmente aniquilado psicológicamente por un tratamiento farmacológico. Igualmente dura es la historia del médico Francisco Piñol, que trabajó como taquígrafo en El Diluvio y llevó a su director 
a conocer las realidades más sórdidas del barrio chabolista de Pekín. Piñol acabaría trágicamente con su vida lanzándose al mar durante la travesía del Atlántico.

En cambio, Claramunt colma de elogios la figura de Ángel Samblancat, abogado y periodista que fue redactor de El Diluvio, colaborador de muchas otras publicaciones y promotor de algunas de fuerte espíritu de reivindicación social. Claramunt presenta al periodista como un discípulo de Juan Costa y le dibuja como un terrible polemista que pasaba temporadas en la cárcel o perseguido por la policía pues "cada uno de sus artículos daba margen a uno o varios procesos". Samblancat también tuvo una faceta en la política activa, cuando formó parte de las Cortes Constituyentes de la Segunda República. Allí mostró el radicalismo de sus ideas (formó parte del grupo etiquetado como los jabalíes) que acabaron impulsando su abandono de la cámara. De hecho, Samblancat tenía simpatías por el movimiento libertario y lideró la toma de la Audiencia Provincial de Barcelona en los primeros días de la guerra civil. Claramunt le dedica también elogios literarios para acabar consignando que Samblancat le ha enviado un ejemplar de su último libro desde México, donde se encontraba exiliado en ese momento.

Jaime Claramunt añade un par de notables a la nómina de sus amigos periodistas. El primero es Luis Bonafoux, el legendario corresponsal de Heraldo de Madrid en París. Le califica de panfletista terrible y afirma de él que podría competir con los mejores escritores franceses del género. Aunque no llegaran a conocerse personalmente, Claramunt fue el responsable de llevar la firma de Bonafoux a las páginas de El Diluvio.

Otro ilustre al que sí conoció bien Claramunt fue el dibujante Luis Bagaria, que ganaría un puesto en la posteridad con sus viñetas en las páginas de EI Sol. Según explica Claramunt, los primeros pasos de Bagaria los dio en el suplemento semanal El Diluvio Ilustrado que él dirigió algunos años.

Las conferencias en la radio habanera también rescatan a personajes olvidados. Miguel Toledano es uno de ellos, escritor satírico y amante del buen vivir, parece el prototipo de bohemio con algo de granuja que complace el gusto de Jaime Claramunt. Otro fue Divaldo Salom, de nacionalidad cubana, poeta y cónsul en Palma de Mallorca. Salom escribió colaboraciones en El Diluvio y terminó su vida con un trágico suicidio. También dedica un recuerdo Claramunt a Joaquín Bartrina, poeta y periodista nacido en Reus que murió prematuramente a los treinta años dejando una profunda huella de humanidad y amor por la libertad. 


\section{Las ideas políticas ${ }^{4}$}

Jaime Claramunt demuestra su honda filiación republicana comparando los dos periodos de la historia de España en que ese tipo de régimen político estuvo vigente. Afirma que en la primera república abundaron los hombres íntegros, pero poco aptos para el gobierno del país. En cambio, en la segunda los idealistas habrían sido minoría frente a un gran grupo de oportunistas y buscavidas. En esta categoría destaca Claramunt a los militantes socialistas, a los que acusa de los mayores actos de corrupción y enchufismo. A Niceto Alcalá Zamora le descalifica por católico ardiente, mientras que deja los más duros epítetos para Alejandro Lerroux, simplemente un traidor a la causa republicana por su alineamiento con las derechas a partir de 1933.

Alaba, en cambio, la actuación de los políticos republicanos, pero sin poner ejemplo alguno. Ni siquiera menciona a Manuel Azaña en ningún momento. Y se permite una declaración solemne de la fe republicana del pueblo español -a fines de los años 40que no habría variado de opinión desde el plebiscito que supusieron las elecciones municipales de 1931. De todo ello se desprende una mentalidad tendente al sectarismo y a un fanatismo de la idea republicana poco contrastada con la realidad.

Claramunt entra en la cuestión catalana a raíz de la muerte de Francesc Macià y la necesidad de encontrarle un substituto en la presidencia de la Generalitat. No duda en calificar de independentista al partido Estat Català de Macià, pero le califica a él personalmente de dirigente pragmático que supo adaptarse a la realidad política de la Segunda República.

Claramunt se atribuye un protagonismo político en el contexto de la incertidumbre por la muerte del presidente Macià. Afirma que fue él quien lanzó la candidatura de Companys a la elección por el parlamento catalán mediante una serie de artículos publicados en El Diluvio.

Su percepción de Lluís Companys -que había sido colaborador del periódico y mantenía una estrecha relación con el editor y con él mismo- era la de un ferviente partidario de la República y un pálido nacionalista. En su comentario sobre la figura de Companys predomina el ángulo psicológico, le califica de persona inestable y tornadiza con múltiples ejemplos y anécdotas.

El futuro presidente de la Generalitat habría aceptado la publicación de los artículos de Claramunt proponiendo su candidatura en una reunión que tuvo lugar en el despacho del director de El Diluvio.

\footnotetext{
${ }^{4}$ Ver las conferencias de Jaime Claramunt agrupadas bajo el epígrafe "Siempre republicanos" en TOLL 2016 p. $147-171$
} 
La consideración de Companys como personalidad influenciable la desarrolla Claramunt en otro pasaje en el que describe su relación con Josep Dencàs, quien fuera conseller de Gobernación en la Generalitat. A Dencàs le retrata como un médico de escaso mérito y político de barrio. Las descalificaciones se suman al narrar su ascenso político a la sombra de Companys y llega a afirmar que pasó "de tonto a loco" cuando llegó a su máxima responsabilidad.

El momento decisivo llegó en octubre de 1934, cuando el presidente de la Generalitat proclamó el estado catalán dentro de la república federal española, todo un desafío al gobierno central que se enfrentaba a una huelga revolucionaria convocada en todo el país. Pues bien, según Claramunt, Companys fue en estos hechos un mero comparsa de Dencàs, que actuó con extremo cinismo dándose a la fuga en la hora de la rendición final.

Claramunt vuelve a recurrir a la descalificación personal para desacreditar a Andreu Nin, el líder del POUM, que trabajó en una etapa de su vida como periodista y estuvo a las órdenes del director de El Diluvio. Le contrató a pesar de los malos informes que sobre él recabara y en los que destaca su participación en el sistema de compra de voluntades del gobernador civil con los periodistas de la ciudad, la llamada sopa. Una paga con dinero procedente del juego que serviría para mantener tranquilas a numerosas plumas de la ciudad, entre las que no se contaba la de Claramunt.

Otro aspecto de Nin que denosta el periodista es su iniciativa para organizar sindicalmente a la profesión y proponer un igual salario para todos los reporteros. A Claramunt le pareció una idea fatal la de no remunerar a los periodistas según su experiencia y mérito profesional. Claramunt recurre a la opinión de Ángel Pestaña para reafirmar la suya, pero es innegable que la propuesta de Nin suponía un avance social que, sin duda, molestaba al responsable de un importante periódico de la ciudad.

El sindicalista Ángel Pestaña es presentado en términos muy elogiosos por su moderación. Claramunt indica que se trata de un amigo personal con el que comparte largas conversaciones en su despacho. Allí, ambos habrían criticado la deriva extremista que, a su juicio, habría tomado el sindicalismo español ya en plena guerra civil.

El autor vuelve al ataque con otro político de la época que se inició como periodista, Joan Moles. Le acusa repetidamente de corrupción y de ineptitud en el ejercicio de sus cargos.

A Domingo Latorre, en cambio, le descalifica solamente por su ingenuidad política, pero considera su honestidad y dedicación a la causa nacionalista que defendía. Aún así, Claramunt no se abstiene de evocar las conversaciones que mantuvieran y en las que el periodista tiraba de la lengua al militante solamente por el gusto de oír sus cándidas afirmaciones. 
Finalmente, Claramunt dedica una de sus conferencias a Josep Anselm Clavé, a quien no tuvo tiempo de conocer, pero a quien hace honores como regenerador de la clase obrera mediante sus iniciativas musicales. Clavé fue asimismo republicano federal, colaborador de Francesc Pi i Margall, considerado el inspirador de la línea editorial de El Diluvio.

De todo lo dicho se desprende que la visión de Jaime Claramunt sobre los personajes políticos que retrata está muy sesgada por sus experiencias personales. Abunda en descalificaciones al hombre $\mathrm{y}$, en cambio, raramente entra en el fondo de las argumentaciones políticas. A lo sumo se limita a constatar su proximidad o lejanía con sus referentes de republicanismo federalista.

\section{La cuestión social ${ }^{5}$}

Jaime Claramunt dedica parte de sus conferencias a tratar asuntos que podríamos definir como crónica roja y negra, pues tienen contenidos político sociales a la vez que elementos propios del mundo de la delincuencia.

Ejemplo perfecto es la conferencia que dedica al asesinato de un personaje turbio del entorno de un cacique político de la ciudad de Barcelona. Con la corrupción como telón de fondo, se explica una intriga sobre la identidad del asesino, la intervención de la policía y un final moralista en el que el asesino es absuelto por la presunta equidad de su acto.

Otra historia relatada por Claramunt refiere el caso de un diputado con aficiones de travestismo y en el que tuvo un especial protagonismo El Diluvio. El periodista conoció la información en exclusiva y administró su publicación para crear un escándalo en la opinión pública sin revelar la identidad del pobre hombre.

Revela así un gusto por aspectos escabrosos de las personas y lo relaciona con la actividad política. Dado que los hechos relatados se producían durante la restauración monárquica, cabe deducir que la intención del autor es la desacreditación del sistema político con medios distintos a los habituales argumentos en defensa del republicanismo.

Destaca también en estas crónicas de Claramunt la elección del tema obrero, otra vez visto desde un punto de vista de cierta truculencia. Así, nos narra el caso de un trabajador torturado por la Guardia Civil por sus actividades reivindicativas. El Diluvio

\footnotetext{
${ }^{5}$ Ver las conferencias de Jaime Claramunt agrupadas como “Crónica roja y negra” en TOLL 2016 p.175198.
} 
habría incidido decisivamente en el caso con su denuncia pública, de lo que el ex director se proclama orgulloso.

De hecho, el autor declara en otra de sus intervenciones su aprecio por "la noble causa obrera". Afirma que, sin ser un diario obrerista, El Diluvio defendió las legítimas reivindicaciones del proletariado. Y sigue una prolija explicación en la que trata de distinguir entre obreros exaltados y razonables, calificando a los primeros de rémora para la República. Añade otra categoría, compuesta directamente por maleantes, que habrían cometido todo tipo de fechorías al amparo de un carné sindical durante la guerra.

El esfuerzo del autor por entender el punto de vista obrero y cuidar a este sector social se ve reflejado también en su conferencia dedicada a la Semana Trágica, la huelga revolucionaria de Julio de 1909. Claramunt desmiente con rotundidad el origen nacionalista del movimiento que fue propagado desde elementos del gobierno central. En cambio explica muy pedagógicamente el malestar de la clase trabajadora por las levas forzosas para la guerra de África que estuvieron en el origen de la explosión de descontento que derivó en la quema de conventos.

La afición del periodista por la crónica negra se refleja en el episodio narrado sobre el atraco al gran casino de Barcelona, cuyos autores utilizaron la sede de El Diluvio como depósito de los bienes que carecían de interés para ellos. Se reflejaba así una relación del periódico con las capas más populares de la ciudad que incluían a los bajos fondos. Sin embargo, Claramunt actuó en esta ocasión para evidenciar ante la policía su voluntad de colaboración con la voluntad de marcar distancias con los autores de los hechos.

Su gusto por el pintoresquismo y los personajes extravagantes se percibe en la crónica dedicada al falso médico que explotaba un aparato de inspección endoscópica del sistema digestivo. El periodista esparce guiños de complicidad con el estafador, que se anunció en las páginas del periódico a pesar de que su director intuyó desde el principio que se encontraba ante un impostor. La altura ética de Jaime Claramunt queda en entredicho en esta y otras ocasiones ya reseñadas.

\section{La guerra civil ${ }^{6}$}

Jaime Claramunt despliega gran aparato crítico en el abordaje de la guerra civil y la actuación de las autoridades republicanas. Reiteradamente afirma que criticó estas

\footnotetext{
${ }^{6}$ Estas conferencias se pueden consultar en TOLL 2016 p. 203-230.
} 
actuaciones en El Diluvio y más concretamente en su sección "crónica diaria", que publicaba en la portada del periódico.

De inicio afirma que él ya advirtió sobre los riesgos de cometer los mismos errores que en la primera República al dejar, por ejemplo, a los militares monárquicos al cargo de importantes responsabilidades. Al parecer de Claramunt, el pueblo español era de sentir republicano y los militares insurgentes no habrían triunfado sin el apoyo de Alemania e Italia.

De estas reflexiones de carácter general, Claramunt pasa a críticas muy concretas de las condiciones de vida durante la guerra en la ciudad de Barcelona.

En primer lugar denuncia el hambre sufrida por la población por la política de abastos de los gobernantes republicanos, tanto centrales como autonómicos, incapaces de llevar a cabo una distribución eficiente de los recursos. Claramunt da veracidad a su relato exponiendo su propia experiencia de infralimentación con descripciones muy gráficas de los nauseabundos caldos que ingirió para sobrevivir.

Otra crítica a las autoridades republicanas fue por la gestión de la política de pasaportes, que en la práctica prohibía la salida legal del país a los ciudadanos que deseaban cruzar la frontera. Claramunt explica sus denuncias en el periódico de esta situación al entender que la población que no tomaba parte en el conflicto armado suponía más un lastre que un beneficio para la causa republicana. Ello le mereció la censura del ministro de la Gobernación, Paulino Gómez Sáiz, que impuso su ley del silencio sobre una decisión que tampoco se molestó en argumentar en una tensa entrevista personal.

Jaime Claramunt también tiene palabras de enojo hacia los controles parapoliciales formados por elementos de lo que él denomina obrerismo exaltado. Una vez más, afirma que denunció las actuaciones irregulares de estos controles en las páginas del periódico. Critica que llegaran a ejercer funciones judiciales en la sombra y se atribuye diversas gestiones en favor de personalidades conservadoras que no merecerían castigo alguno por no haber conspirado contra la República.

La afiliación sindical obligatoria es otro de los objetos de la crítica del periodista exiliado. Con toda rotundidad se opone a la disolución virtual de las clases sociales que supuso esa medida. Le molesta el mero hecho de la afiliación y también la obligación de seguir las órdenes del sindicato en cuestión.

Así, ejemplifica que El Diluvio y su personal estaban afiliados a la Asociación de la Prensa Diaria de Barcelona, que fue incautada por la UGT. De esta forma, el personal del periódico pasó a depender orgánicamente del sindicato socialista, con la paradoja de que solamente uno de los trabajadores tenía simpatía por esa ideología. 
Jaime Claramunt defiende en diversas ocasiones la propiedad privada $y$, coherentemente, se opone a la formación de los comités de control obrero de las empresas que se formaron en la España republicana durante la guerra. A su descalificación genérica suma argumentos de índole personal al afirmar que en los comités no se imponen los trabajadores más capaces, sino que lo hacen los más atrevidos. Su conclusión es que los comités no sirvieron para una mejora de las relaciones entre patronos y obreros como se dijo, sino que avivaron los desacuerdos.

El episodio final que concentra las mayores iras de Jaime Claramunt es la incautación de El Diluvio por la UGT en 1938, cuando el gobierno central se instaló en Barcelona.

Con un lenguaje expresivo lleno de descalificaciones, acusa a los socialistas de apropiarse del periódico La Vanguardia, que había estado en manos de los anarquistas en los primeros años de la guerra. Además, acusa al director del periódico de compatibilizar su sueldo con el del mismo cargo en El Mercantil Valenciano.

En este ambiente, Jaime Claramunt tomó la decisión de arrimar El Diluvio a un partido político y así evitar una incautación por la fuerza. Así llegó a un acuerdo con el presidente del Congreso de los Diputados, Diego Martínez Barrio, para adscribir el periódico a la Unión Republicana.

Sin embargo, Claramunt atribuye a los socialistas una serie de maniobras para presionar a la propiedad del periódico e imponer la voluntad de adscribir a sus filas El Diluvio. Una vez conseguido su objetivo, se le ofreció la subdirección del periódico, pero Claramunt la rechazó, al igual que denegó la posibilidad de escribir como colaborador.

El periodista pasa a explicar cómo le substituyó en la dirección Antonio Huerta, un militante de la UGT del País Vasco al que denigra por sus escasos conocimientos y mediocridad profesional. Le atribuye, además, una acumulación de cargos administrativos que le permitieron llevar un alto nivel de vida en la Barcelona de finales de la guerra civil.

Según Claramunt, los redactores del periódico fueron marginados y en su lugar escribían los colaboradores de Huerta. Asimismo, los lectores habrían dado la espalda al periódico por no reconocer su línea editorial.

Termina el periodista su narración explicando la suerte del periódico tras la entrada de los franquistas en la ciudad de Barcelona. El editor, sus hijos y el jefe de redacción fueron encarcelados. Manuel de Lasarte moriría en la cárcel de una afección renal a los pocos meses de su ingreso. La maquinaria fue trasladada a la prisión de Alcalá de Henares, donde sirvió para imprimir el semanario Redención. Claramunt barruntaba desde Cuba que la colección completa del periódico habría desaparecido pasto de las llamas a manos de los falangistas. Sin embargo, sí se conservaron dos colecciones del 
periódico que hoy se pueden consultar en la Hemeroteca Municipal de Barcelona y en la Biblioteca de Catalunya ${ }^{7}$.

\section{Conclusiones}

El hallazgo y difusión de las memorias de Jaime Claramunt consituyen un importante avance en el conocimiento de la historia del diario El Diluvio. El periodista cubano dirigió el periódico durante más de dos décadas, incluyendo el fundamental episodio de la Segunda República española.

El Diluvio fue un periódico fundamental en la expresión de los puntos de vista de federalistas, obreristas, anarquistas y catalanistas en un mismo medio de comunicación. Su estudio, hasta el momento, es muy limitado y se ciñe a las primeras etapas del diario (Argemí, 1998; Pich, 2003).

El conocimiento de las memorias de Jaime Claramunt viene a corregir en parte este déficit, que se agrava si se considera que los puntos de vista expresados en el periódico coinciden con los de los sectores que apoyaron, con altos y bajos, la Segunda República en Catalunya y el Gobierno de la Generalitat, también durante la Guerra Civil.

Jaime Claramunt personifica mejor que nadie esta síntesis de pensamiento que él expresó a través de sus artículos diarios. Una firme adscripción republicana, una gran sensibilidad por la problemática de la case obrera y una concepción federalista del Estado que le lleva a defender el estatuto de autonomía de Catalunya.

El Diluvio no fue un periódico innovador en lo periodístico. Su presentación formal estuvo muy anticuada hasta la revisión que se realizó en 1933. Tampoco destacó en el uso de géneros periodísticos modernos, como la entrevista o el reportaje. En cambio, publicaba a menudo textos ajenos sin apenas revisión. Este déficit profesional se convertía en virtud de conexión con un público lector acostumbrado a sus hechuras y sabedor de la tolerancia del periódico a la hora de publicar denuncias de colectivos o entidades que simpatizaban con su línea editorial.

Sin duda es preciso que se estudie ampliamente la historia de este periódico fundamental en el periodismo barcelonés por más de ocho décadas y que se ponga fin a un silencio inicialmente impuesto por los vencedores de la guerra civil y posteriormente consentido por las generaciones de la democracia.

\footnotetext{
${ }^{7}$ De hecho, el periódico ha sido digitalizado en fechas recientes y se puede consultar en http://www.bnc.cat/digital/arca
} 


\section{Referencias bibliográficas}

ARGEMÍ, Anna (1998) El Telégrafo/La Imprenta, (1858-1879) El primer diari informatiu i popular de Barcelona, Trabajo de fin de carrera UPF

CUADRIELLO, Jorge Domingo (2009) El exilio republicano español en Cuba, Madrid Siglo XXI

DALMAU, Antoni (2010) El Procés de Montjuich, Barcelona, Editorial Base

FOIX, Pere (1976) Apòstols i mercaders, Seixanta anys de lluita social a Barcelona, Barcelona, Editorial Nova Terra,

GUILLAMET, Jaume (2010) L'arrencada del periodismo liberal, Vic, Eumo editorial

PICH, Josep "Manuel de Lasarte Rodríguez Cardoso i els inicis de la premsa catalana de masses" Treballs de comunicació num 18 (desembre 2003) p.87-106.

ROURE, Conrad (2010) Recuerdos de mi larga vida, Vic, Eumo editorial

TOLL, Gil (2016) El Diluvio, memorias de un diario republicano y federalista de 18581939, Barcelona, Carena

(2013) Heraldo de Madrid, tinta catalana para la II República española, Sevilla, Renacimiento 